\title{
Full Factorial Design Analysis and Characterization of Polyethylene, Starch and Aloe Vera Gel Thin Film Formulation
}

\author{
Siti Fatma Abd Karim a , Junaidah Jai a, ${ }^{\text {a }}$, Ku Halim Ku Hamid a , Mohd Hariz Mior Muzamin a, \\ Nadia Kamarrudin a, Rabiatul Adawiyah Abdol Aziz ${ }^{\text {a }}$ \\ ${ }^{a}$ School of Chemical Engineering, College of Engineering, Universiti Teknologi MARA, (UiTM) Shah Alam, 40450 Selangor, Malaysia \\ Corresponding author: ${ }^{*}$ junejai@uitm.edu.my
}

\begin{abstract}
The polyethylene-thermoplastic (PE/TPS) based film was introduced many years ago, but the compatibility of PE/TPS still an issue because synthetic compatibilizer has a safety drawback. In this work, aloe vera (AV) was introduced as a compatibilizer to enhance stress and characteristics of PE/TPS film. This paper determines the optimum PE/TPS/AV film formulation using full factorial design (FFD) analysis. Melt blending and hot-press techniques were used to prepare the film. Four selected PE/TPS/AV samples were chosen to discuss mechanical properties, functional groups, thermal degradation, and thermal properties changes. Based on FFD, PE was the most significant material that caused substantial changes in the film's mechanical properties. Concurrently, the interaction between PE/TPS and TPS/AV significantly influenced the value of the secant modulus. The addition of AV into TPS improved the stress and reduced the strain. New peaks are present in TPS/AV that share the same functional group with PE. Thus, improving the stress of the film. The presence of AV caused peaks $2916 \mathrm{~cm}^{-1}$ and $2849 \mathrm{~cm}^{-1}$ of TPS to strengthen at once; the thermal degradation increases tremendously from $282{ }^{\circ} \mathrm{C}$ to $354.70{ }^{\circ} \mathrm{C}$. The melting temperature showed a reduction when TPS/AV was added into PE, but the crystallization temperature did not significantly change. However, significant changes occurred for crystallization enthalpy when TPS/AV was incorporated in PE at once, affecting the degree of crystallinity. In conclusion, AV was suggested to act as a compatibilizer/crosslinker or plasticizer to improve $\mathrm{PE}$ film packaging properties.
\end{abstract}

Keywords - Full factorial design; design expert; thin film; polyethylene-starch film; Aloe vera gel.

Manuscript received 25 May 2021; revised 26 Jun. 2021; accepted 2 Sep. 2021. Date of publication 31 Dec. 2021. IJASEIT is licensed under a Creative Commons Attribution-Share Alike 4.0 International License.

(c) (i) (?)

\section{INTRODUCTION}

The development of degradable plastic increases every year since the government wants to eliminate unavoidable plastic waste and move towards a more circular economy. The combination of polyethylene (PE) and thermoplastic starch (TPS) has become an alternative by researchers in improving the degradation ability of PE film and enhancing the mechanical properties of TPS film [1]. TPS added reduced the mechanical properties of PE film because of high moisture sensitivity [2]. Unfortunately, the combination between PE/TPS caused high interfacial tension [3] due to the hydrophilic nature of $\mathrm{PE}$ and the hydrophobic nature of starch [4]. Compatibilizer was introduced for better dispersion of TPS in PE matrix at once, enhancing the mechanical performance [3].

Common PE-based compatibilizers are polyethylene grafted maleic anhydride (PE-g-MA) [2], [5], ethylene acrylic acid copolymer (EAA) [5], polyethylene-covinyl alcohol, and synthetic polymer grafted with acrylamide [6]. Starch-based compatibilizers examples are starch-g-poly(acrylic acid), stearic acid-grafted starch [7] and octanoate starch (OCST) [8]. PE-based compatibilizer modifies the surface of PE [9], while starch-based improve the starch hydrophobic character to enhance the distribution of starch [10].

The addition of PE-g-MA did not encourage results, especially on mechanical performance [11]-[13]. Besides, the toxic properties in PE-g-MA had limited its application in food packaging material due to safety concerns [14], [15]. Therefore, additives or filler have been added into PE/TPS film to improve the film performance, such as green tea powder [16], starch nanoparticles [17], cellulose nanocrystals [18], and organic acid [19]. The results on the film's mechanical properties seem promising because they improved. However, others found that organic material such as ethylenediaminetetraacetic acid (EDTA) and date seed extract decreased the mechanical properties [20]. 
Aloe vera gel consists of a clear inner gel composed of $99 \%$ water [21] and some active components such as phenolics, sugar, amino acids, saponins, and minerals [22]. A few researchers used AV in film sheet packaging [21]-[24]. AV being used as a function of antimicrobial agent [23], antifungal agent [25], bioplasticizer [26], or as a crosslinking agent [21], [27]. AV can form a thicker starch film by improving the crosslink in the starch matrix [24]. Thus, affecting the crystallinity, morphology, and mechanical properties. The organic acid present in AV improves compatibility between plasticizer-starch. In addition, avoiding intermolecular interactions between the macromolecules of starch [24]. This condition causes higher hydrogen bonding interactions between AV and starch, resulting in smooth and compact morphology [21]. Other research found a reduction in hydrophilic groups in chitosan starch to interact with water when AV is presented in the film [28].

Full factorial design (FFD) technique from Design-Expert software was a method to study the effect of each factor towards the decided response variables and the effect of factors interaction. There is a limited study conducted on using FFD for optimizing PE/TPS starch formulation. Verma [29] used 32 FFD to develop a fast-dissolving film of chitosan embedded famotidine. At the same time, Vundadda [30] applied 32 experiments to evaluate the influence of plasticizer type and concentration on film performance. The experimental design technique proved a helpful tool in assessing the factors that change the response variables result. Experimental design quantified each process's effect, demonstrating variables interactions to the potential surface decay of polyethylene terephthalate film. Therefore, this paper consists of two sections: 1) determination of optimized PE/TPS/AV film using FFD technique; 2) To discuss the changes upon addition of TPS/AV into mechanical properties and characteristics of PE-film.

\section{MATERIALS AND METHOD}

\section{A. Materials}

Low-density polyethylene (MW:0.915 g/ $\mathrm{cm}^{3}$, Lotte Chemical, Titans, Malaysia), potato soluble starch (Bendosen, Malaysia), Glycerine (MW:92.094 g/mol, 99.5\% USP, Inscent, Malaysia), Aloe Vera (Chemieconnex, Malaysia).

\section{B. Design of Experiment (Full Factorial Design)}

The purpose of conducting a two-level full factorial design was to determine the factors that significantly influenced the experiment's outcome. The range for PE and TPS was between $40-70 \%$ and $30-60 \%$ of the total weight, respectively, because more than $30 \%$ guarantees film degradability satisfaction [31], [32]. The lower and upper limit for AV concentration was obtained from preliminary testing on the combination of PE/AV [33] with some modifications to prevent the negative value suggested by FFD. The formula obtained is presented in Table 1.

\section{Film Preparation}

The film prepared was based on a previous method conducted [33]. Pre-mixed raw materials started in Banbury Thermo Haake Polylab Internal mixer at $160^{\circ} \mathrm{C}, 60 \mathrm{rpm}$. The mixture was considered homogeneous when constant torque occurred for around 6 minutes, as pictured in Fig. 1. The crushing process in Rexmac Compact Crusher continued after the mixture became homogenous to get small resin parts to enhance consistent heat transfer distribution during hot-press. Then, the crushed resin was compressed using Cometech Hot Press at three stages condition which was, 1) pre-heat for 10 minutes on $130{ }^{\circ} \mathrm{C}$ to ensure consistent heat transfer occurred throughout the sprinkled resin on the plate, 2) hot-pressed for 10 minutes, $130^{\circ} \mathrm{C}$ with 700 psi pressured, and 3) cooled the film to $40{ }^{\circ} \mathrm{C}$ while tab water was running. Finally, the film then peeled off from the plate. The formulation was based on calculated value from full factorial design (FFD), as stated in Table 1.

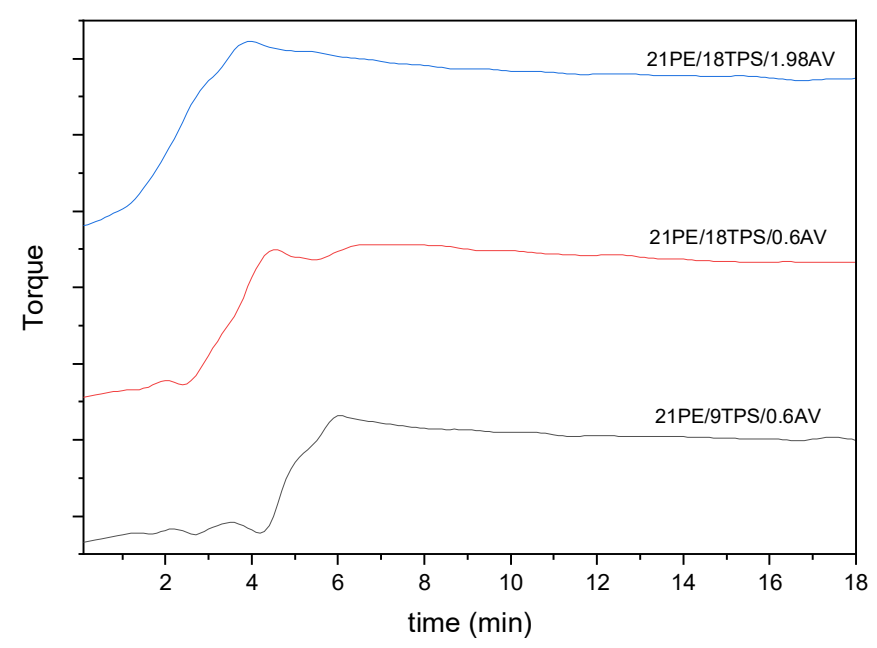

Fig. 1 Torque value monitored for all prepared films.

\section{Film Characterization}

The characterization started with measuring the mechanical properties of the samples since it was the primary performance required for thin film. Universal Testing Machine (Instron 3382) used at $25 \mathrm{~mm} / \mathrm{min}$ strained rate. The film dimension is based on ASTM D882 (100 mm length x 25 $\mathrm{mm}$ width). The raw materials and films then underwent a few testings using Fourier Transformed Infrared Spectroscopy (FTIR, Mettler Toledo), Gravimetric Analyzer instrument (TGA, TGA/SDTA581, Mettler Toledo), and Differential Scanning Calorimetry (DSC, Mettler Toledo) instruments for further characterization.

FTIR spectrum shows the $\%$ transmittance at the range of frequency between $515-4000 \mathrm{~cm}^{-1}$, at $4 \mathrm{~cm}^{-1}$ resolutions. The IR transmittance spectra show the presence of a functional group in the thin films. The thermal degradation properties (weight loss) were measured using TGA, $20 \mathrm{mg}$ sample at a temperature range of $25-600{ }^{\circ} \mathrm{C}, 10^{\circ} \mathrm{C} / \mathrm{min}$ heating rate, and under $50 \mathrm{ml} / \mathrm{min}$ flow of nitrogen atmosphere. Thermal properties were taken from DSC using a cycle process using $5 \mathrm{mg}$ samples and a $50 \mathrm{ml} / \mathrm{min}$ flow rate of nitrogen. First, heating $\left(25\right.$ to $190{ }^{\circ} \mathrm{C}$ ) is considered to remove the film's thermal history. Cooling (190 to $-10{ }^{\circ} \mathrm{C}$ ) was applied to determine the crystallization temperature, while second heating $\left(-10\right.$ to $\left.190{ }^{\circ} \mathrm{C}\right)$ to obtain the melting temperature of the film. 


\section{RESULT AND DISCUSSION}

The discussion was divided into part 1 and part 2 .

\section{A. Part 1: optimizing the formula using FFD}

This section covered the film's appearance and the determination of optimized sample formula based on FFD.

1) The film's visual appearance: Fig. 2 displays the film's visual appearance from the naked eye. All films stand alone, showing the uniform condition, and are easily removed from the hot metal plate. The thickness is then measured because it is an essential character for using the film for packaging.

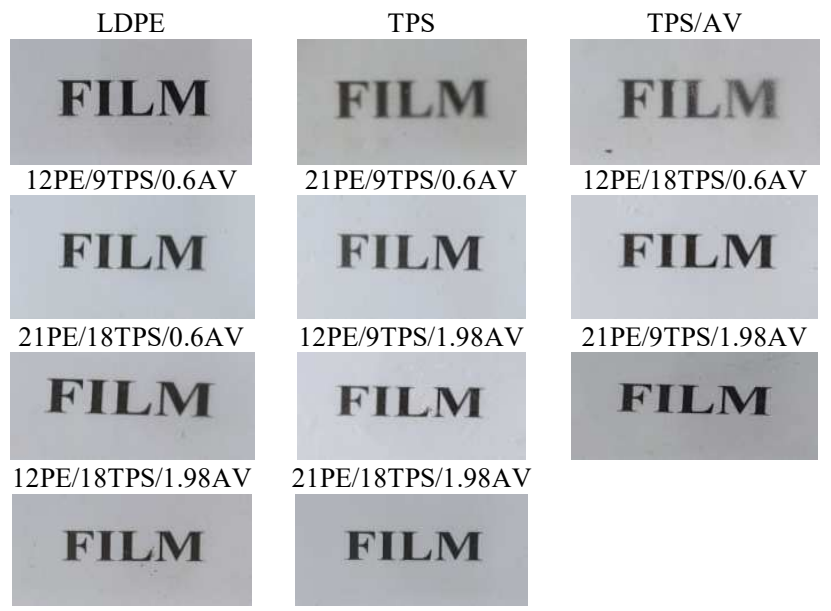

Fig. 2 Visual appearance of films for pure PE, TPS, TPS/AV, and $\mathrm{PE} / \mathrm{TPS} / \mathrm{AV}$ at a different formulation
2) Preliminary analysis of FFD: Table 1 tabulated the results inserted into FFD in DesignExpert11 trial software. The data obtained from Table 1 were converted into the preliminary analysis, as shown in Fig. 3. The correlation value is represented by the red (positive correlation, +1 ) or blue (negative correlation, -1) color. Based on Fig. 3, PE has the highest negative correlation on thickness with -0.658 , while strong positive correlation on ultimate stress, ultimate strain, break stress, break strain, and break energy, with $0.885,0.797$, $0.848,0.726$, and 0.864 , respectively. TPS and AV concentration do not positively or negatively correlate because the pale red and pale blue color showing value less than 0.5 represents a weak correlation. From preliminary analysis, PE would have a significant impact on ultimate stress, ultimate strain, break stress, break strain, and break energy. However, further discussion was needed to support the preliminary analysis conclusion.

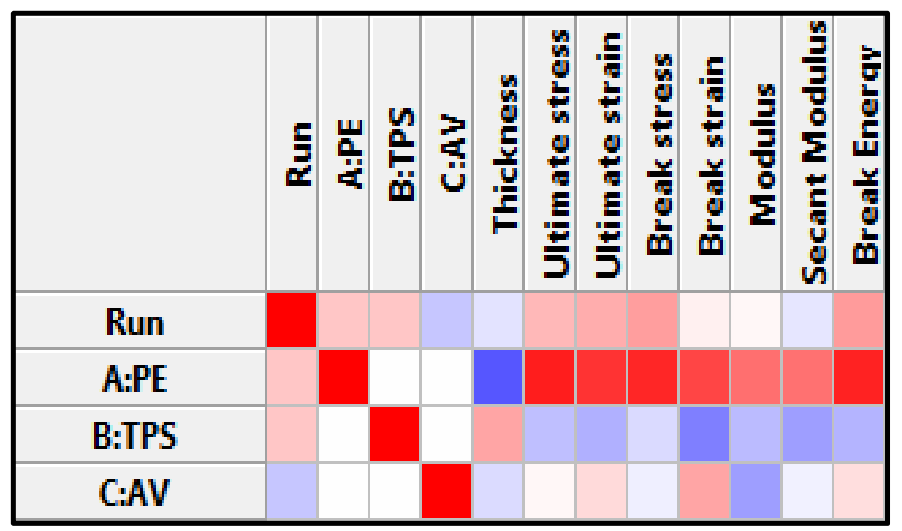

Fig. 3 The correlation obtained during pre-analysis data

TABLE I

THE RESULTS OBTAINED FROM THE EXPERIMENT

\begin{tabular}{|c|c|c|c|c|c|c|c|c|c|c|c|}
\hline No & $\begin{array}{l}\text { PE } \\
\text { (g) }\end{array}$ & $\begin{array}{l}\text { TPS } \\
\text { (g) }\end{array}$ & $\begin{array}{l}\text { AV } \\
\text { (g) }\end{array}$ & $\begin{array}{l}\text { Thickness, } \\
\text { Thick (mm) }\end{array}$ & $\begin{array}{l}\text { Ultimate } \\
\text { stress, UT } \\
\text { (MPa) }\end{array}$ & $\begin{array}{l}\text { Ultimate } \\
\text { strain, US } \\
(\%)\end{array}$ & $\begin{array}{l}\text { Break } \\
\text { stress, } \\
\text { BT } \\
\text { (MPa) }\end{array}$ & $\begin{array}{l}\text { Break } \\
\text { strain, } \\
\text { BS (\%) }\end{array}$ & $\begin{array}{l}\text { Modulus, } \\
\text { Mod } \\
\text { (MPa) }\end{array}$ & $\begin{array}{l}\text { Secant } \\
\text { Modulus, } \\
\text { S.Mod } \\
\text { (MPa) }\end{array}$ & $\begin{array}{l}\text { Break } \\
\text { Energy, } \\
\text { BE } \\
\left(\mathrm{MJ} / \mathbf{m}^{3}\right)\end{array}$ \\
\hline 1 & 12 & 9 & 0.6 & 0.205 & 3.40 & 5.6 & 3.17 & 6.0 & 102.63 & 97.83 & 41167 \\
\hline 2 & 21 & 9 & 0.6 & 0.177 & 5.13 & 9.1 & 5.01 & 9.6 & 101.27 & 100.43 & 398000 \\
\hline 3 & 12 & 18 & 0.6 & 0.275 & 1.99 & 3.8 & 1.69 & 4.9 & 66.07 & 52.67 & 64600 \\
\hline 4 & 21 & 18 & 0.6 & 0.183 & 4.36 & 8.0 & 4.19 & 8.4 & 107.63 & 88.50 & 240267 \\
\hline 5 & 12 & 9 & 1.98 & 0.220 & 1.78 & 3.9 & 0.45 & 8.3 & 75.03 & 75.13 & 57800 \\
\hline 6 & 21 & 9 & 1.98 & 0.182 & 6.12 & 12.9 & 6.00 & 12.9 & 92.67 & 84.90 & 520000 \\
\hline 7 & 12 & 18 & 1.98 & 0.202 & 2.76 & 5.8 & 2.61 & 6.1 & 83.40 & 78.67 & 88300 \\
\hline 8 & 21 & 18 & 1.98 & 0.205 & 4.50 & 7.0 & 4.21 & 8.1 & 86.07 & 94.90 & 241667 \\
\hline
\end{tabular}

3) Detail analysis of FFD: The results from the screening experiment illustrated in Table 2 showed that the influence of PE, TPS, and AV was found significant $(p<0.05)$ within the selected range. Only thickness and modulus gave nominal value for all factors. The most significant factor was $\mathrm{PE}$ which significantly affected most of the mechanical properties of the film. AB significantly affects the secant modulus and break energy, while the interaction between $\mathrm{BC}$ significantly influences the secant modulus only. Secant modulus represents the material's rigidity, which is the higher flexibility obtained with a higher modulus of elasticity. The suggested optimum PE, TPS, and AV suggested optimum value was $18.91 \mathrm{~g}, 16.54 \mathrm{~g}$, and $0.84 \mathrm{~g}$, respectively, with the expected mechanical properties as shown in Table 3. The value was obtained from the optimization analysis of the preliminary data using FFD analysis. The validation experiment was then conducted, and the percentage of error percentage was calculated to compare the predicted and experimental values for the optimized formula suggested by FFD. Thickness, ultimate stress, and break stress show less than $5 \%$ error, while other properties show a vast error. The discussion proceeded on AV and TPS ratio's effect on stressstrain, functional group, thermal degradation, and thermal properties of PE film. Four samples with the highest stress 
value have been selected from 13 samples listed in Table 1 for further characterization.

TABLE II

EXPERIMENTAL RESULTS OF FFD IN IDENTIFYING THE MOST SIGNIFICANT FACTOR

\begin{tabular}{|c|c|c|c|c|c|c|c|}
\hline 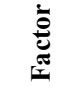 & $\varangle$ & 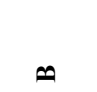 & U & 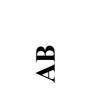 & 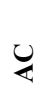 & U & $\underset{\ell}{\ell}$ \\
\hline Res & \multicolumn{7}{|c|}{$p<0.05$} \\
\hline Thic & - & - & - & - & - & - & - \\
\hline UT & 0.0035 & - & - & - & - & - & - \\
\hline US & 0.0179 & - & - & - & - & - & - \\
\hline BT & 0.0078 & - & - & - & - & - & - \\
\hline BS & 0.0106 & 0.0358 & 0.0963 & - & - & - & - \\
\hline Mod & - & - & - & - & - & - & - \\
\hline SMod & 0.0341 & 0.0871 & - & 0.1064 & - & 0.0268 & - \\
\hline $\mathrm{BE}$ & 0.0008 & 0.0381 & - & 0.0174 & - & - & - \\
\hline
\end{tabular}

A - PE, B - TPS, C - AV

Res (Response), Thic (Thickness), UT (Ultimate stress), US (Ultimate strain), BT (Break stress), BS (Break strain), Mod (Modulus), SMod (Secant modulus), BE (Break energy)

TABLE III

PERCENTAGE ERROR FOR THE OPTIMUM VALUE OF COMPOUNDING

\begin{tabular}{llll}
\hline Properties & $\begin{array}{l}\text { Predicted } \\
\text { Value }\end{array}$ & $\begin{array}{l}\text { Experimental } \\
\text { Value }\end{array}$ & $\begin{array}{l}\text { \% } \\
\text { Error }\end{array}$ \\
\hline Thickness & 0.2000 & 0.2060 & 3.00 \\
Ultimate stress & 4.40 & 4.60 & 4.55 \\
Ultimate strain & 8.20 & 5.16 & 37.07 \\
Break Stress & 4.80 & 4.90 & 2.08 \\
Break strain & 7.60 & 6.10 & 19.74 \\
Modulus & 94.90 & 123.00 & 29.61 \\
Secant Modulus & 82.30 & 135.00 & 64.03 \\
Break Energy & 228913.24 & 208000 & 9.14 \\
\hline
\end{tabular}

B. Part 2: The effect of TPS and AV concentration towards characteristics of $P E$

1) Stress-Strain: Fig. 4 displays the ultimate stress value for all films, while Fig. 5 shows the ultimate strain obtained for all films. The combination of TPS with PE reduced PE's but increased TPS's stress and strain and has been mentioned by a few researchers before [18], [34]. From Fig. 4, the highest stress obtained was $6.1167 \mathrm{MPa}$ for 21PE/9TPS/1.98AV, and the same film shows the highest strain at $12.93 \%$, as presented in Fig. 5. At $0.6 \mathrm{~g}$ or $1.98 \mathrm{~g} \mathrm{AV}$, the addition of more TPS reduced the stress because it functioned as a reinforcing agent to improve the degradation ability of PE film but reduced the stress. Besides, because of the hydrogen bonding in the starch structure that stiffer [13]. This behavior is commonly found in PE reinforced with biodegradable polymer [11], [14], [35].

At $9 \mathrm{~g}$ TPS, the stress reduced with a higher amount of AV, while at $18 \mathrm{~g}$ TPS, the stress slightly increased with a higher amount of AV. The stress improved due to the presence of fatty acid in AV. AV acted as a crosslinker that toughens the internal bonds of biopolymers (TPS). The fatty acid could also act as a plasticizer (hydroxyl group) or crosslinker (carbonyl group). AV served as a crosslinker at high TPS, strengthening the intermolecular binding by covalent bonds, increasing the stress. Higher AV had caused AV to act as a plasticizer at a lower TPS amount, thus reducing the stress. Similar results were obtained by others, where a certain amount of citric acid improves stress [22].
For the strain, at $0.6 \mathrm{~g}$ or $1.98 \mathrm{~g} \mathrm{AV}$, the addition of $9 \mathrm{~g}$ of TPS reduced the strain by $15 \%$ and $26 \%$, respectively. Sabetzadeh [35] mentioned that thermoplastic oxidized starch added into linear low-density polyethylene (LLDPE) and lowdensity polyethylene film caused a reduction in stress and strain due to the starch acting as a reinforcing agent that weakening the interfacial interactions between polymers. The strain of LLDPE decreases upon the addition of TPS due to a weak interface between LLDPE and TPS that leads to TPS aggregation [13]. However, more AVs gave higher strain at $9 \mathrm{~g}$ of TPS because AV acted at the plasticizer. The ratio of TPS and AV influenced the stress and strain value. It shows that the optimization process is crucial to determine the best formulation that contributes to good stress and strain value.

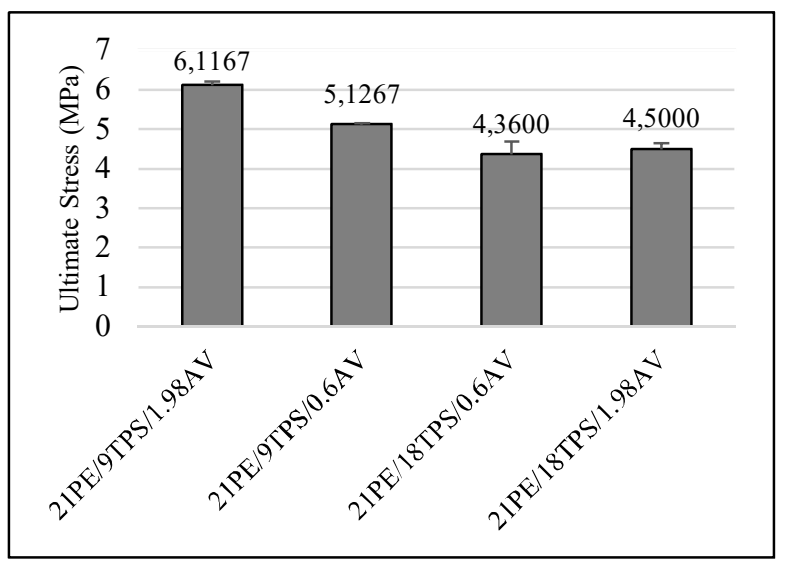

Fig. 4 The ultimate stress value of PE/TPS/AV films

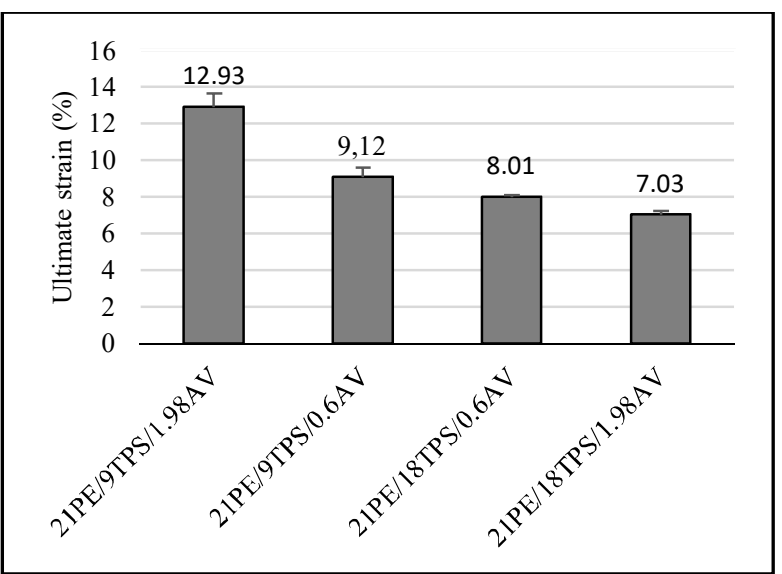

Fig. 5 The ultimate strain value of PE/TPS/AV films

2) FTIR: The FTIR spectra obtained for AV gel, TPS, PE, TPS/AV, and PE/TPS/AV were shown in Fig.6 and Fig. 7. The peaks were then summarized and tabulated, as represented in Table 4. Based on Table 4, AV and TPS both show $\mathrm{O}-\mathrm{H}$ functional groups representing water in the material. TPS contained physiosorbed water [34], while AV gel consists of $98-99 \%$ water [36]. A combination of TPS and $\mathrm{AV}$ had narrowed the peak of $\mathrm{O}-\mathrm{H}$ functional group at $3289 \mathrm{~cm}^{-1}$. The combination of TPS and AV had caused intense peaks obtained, which peak $2915 \mathrm{~cm}^{-1}$ and $2849 \mathrm{~cm}^{-1}$ due to fatty acid in $\mathrm{AV}$, which resembles significant peak occurrence in PE film structure. Reference [37] found that the same peak shifted in potato starch when fatty acid was added to it. The typical peak observed for PE were $2915 \mathrm{~cm}^{-1}$ and $2849 \mathrm{~cm}^{-1}$, a medium C-H stretching of the alkane functional 
group [38]. An almost similar peak for LDPE has also been observed by reference [39]. $1640 \mathrm{~cm}^{-1}$ from AV and 1647 $\mathrm{cm}^{-1}$ from TPS representing carbonyl group of cellulose in AV and TPS [40] has shifted, and the peak becomes smaller at $1652 \mathrm{~cm}^{-1}$, TPS/AV form two new peak which was 1464 $\mathrm{cm}^{-1}$ and $718 \mathrm{~cm}^{-1}$ which created the same C-H bending and rocking vibration of methylene groups that majorly shown in PE FTIR spectrum. Thus, it suggested that AVs' addition to TPS can increase the hydrophobic character of TPS by forming a PE functional group.

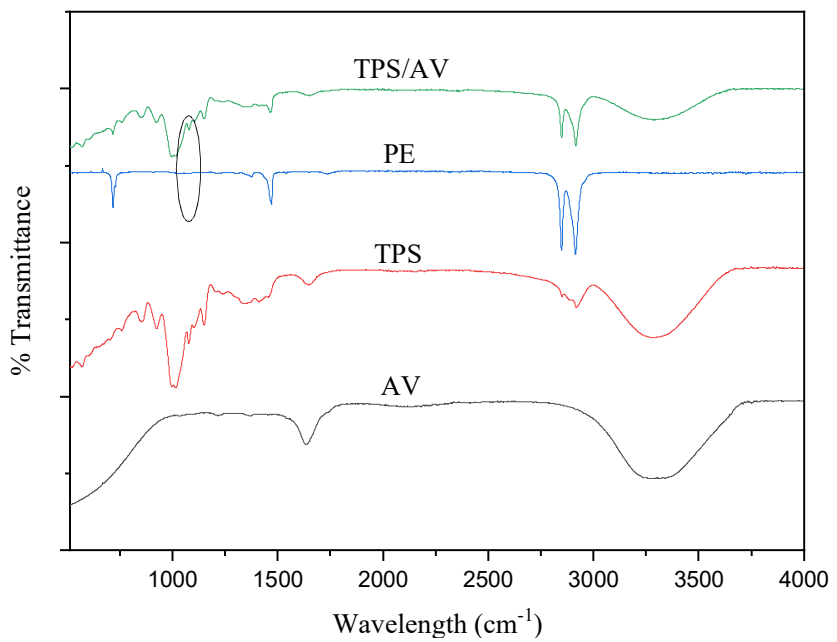

Fig. 6 FTIR spectrum for AV, TPS, PE and TPS/AV

Based on Fig. 7, significant peaks were observed in the $\mathrm{PE} / \mathrm{TPS} / \mathrm{AV}$ combination were $3318 \mathrm{~cm}^{-1}$. The signal at 3300 $\mathrm{cm}^{-1}$ correspondingly to the hydroxyl group's stretching vibrations $(-\mathrm{OH})$ of the glucosidic unit of starch. It showed a decrease in its intensity due to the chemical interaction with the functional group of PE [41]. A more prominent and sharper peak was obtained at $2915 \mathrm{~cm}^{-1}$ and $2848 \mathrm{~cm}^{-1}$ than TPS/AV, suggesting that interaction happened between PE and TPS/AV. More TPS amount had caused $1738 \mathrm{~cm}^{-1}$ to sharpen because of a stronger sense of the existence of $\mathrm{C}=\mathrm{O}$ stretching for the ester group in this combination. This interaction occurred due to the interaction between starch and glycerol (plasticization effect) in TPS formation [42]. The results improve with a higher amount of AV at constant PE/TPS because the fatty acid in AV indicates the crosslinking with TPS [37]. Between 515 to $1500 \mathrm{~cm}^{-1}$, the spectrum was the fingerprint region for polymer blends [14]. The above findings concluded that there is a chemical interaction between PE and TPS/AV. Thus, enhancing adhesion between PE and TPS and at once better stress obtained. Camilo et al. [43] predicts the mechanical properties of wey-protein film using FTIR and chemometric tools. The findings concluded that FTIR profiles coupled to chemometric tools could be adequate to predict mechanical properties of the wey-protein film under accelerated ageing conditions.

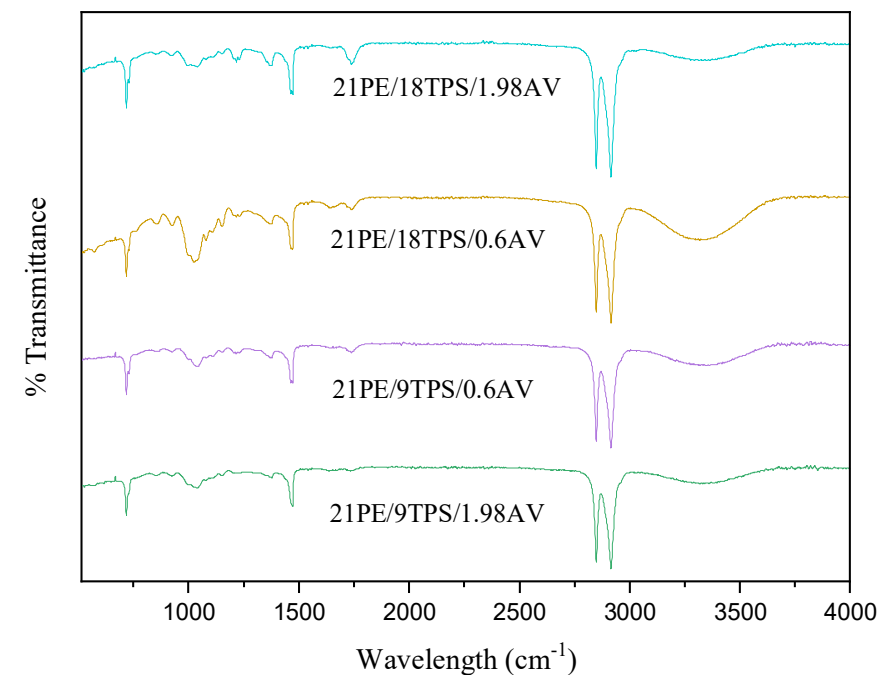

Fig. 7 FTIR spectrum for the combination of PE/TPS/AV at different amounts of TPS and AV

TABLE IV

SIGNALS OF THE FTIR SPECTRA

\begin{tabular}{|c|c|c|c|c|c|}
\hline Sample / functional group present & $\mathbf{A V}$ & TPS & PE & TPS/AV & PE/TPS/AV \\
\hline Stretching vibration $\mathrm{O}-\mathrm{H}$ & 3275 & 3288 & - & 3289 & 3318 \\
\hline Stretching vibration C-H (methyl and methylene group) & - & 2920 & 2915 & 2916 & 2915 \\
\hline Stretching vibration C-H (methoxy group) & - & - & 2849 & 2849 & 2848 \\
\hline Stretching vibration $\mathrm{C}=\mathrm{N}$ & 2159 & - & - & - & - \\
\hline Stretching vibration $\mathrm{C}=\mathrm{O}$ & 1640 & 1647 & - & 1652 & 1738 \\
\hline Bending C-H & - & - & 1471 & 1464 & - \\
\hline Deformation vibration $\mathrm{CHy}-\mathrm{CH}_{2}$ & - & 1334 & 1377 & - & 1366 \\
\hline Stretching vibration C-O & - & 1150,1077 & - & 996 & 1217,1040 \\
\hline Stretching vibrations of glycosidic linkages alpha 1-6 & - & 925 & - & - & - \\
\hline Skeletal vibration of the methylene groups $\mathrm{CH}_{2}$ & - & - & 718 & - & 718 \\
\hline
\end{tabular}

*All values in $\mathrm{cm}^{-1}$

3) TGA: Fig. 8a shows the thermogravimetric graph for the AV gel, glycerine, starch powder, TPS film, PE film, and TPS/AV film, while Fig. $8 \mathrm{~b}$ represents the derivative thermogravimetric condition of all samples. Generally, based on Fig. 8a and Fig. 8b, only one degradation peak was observed at samples except for starch powder (two degradation peaks). AV gel shows the degradation started as soon as the heating was applied to the material, and it completely degraded at $100{ }^{\circ} \mathrm{C}$ with a degradation rate of 3.88 $\mathrm{mg} / \mathrm{min}$. Khor [44] found that AV gel weight declined when the heat was applied to the sample, and significant burn happened towards $\mathrm{AV}$ at $110^{\circ} \mathrm{C}$. It completely degraded at $130{ }^{\circ} \mathrm{C}$. The decomposition temperature $\left(\mathrm{T}_{\mathrm{d}}\right)$ of TPS started at $50{ }^{\circ} \mathrm{C}$ that, representing the decrement of physisorbed water molecules that resulted during the sample preparation. Datta [45] found the water molecule in LDPE/starch/silica vaporize 
and decompose at a temperature of $90{ }^{\circ} \mathrm{C}$, while Liu [46] obtained the starch decompose immediately when the temperature rises and end at $110^{\circ} \mathrm{C}$. The constant degradation rate occurred at TPS from the starting heating process, representing the evaporation of water and glycerine-rich phases, which results from a similar result obtained by others [47].

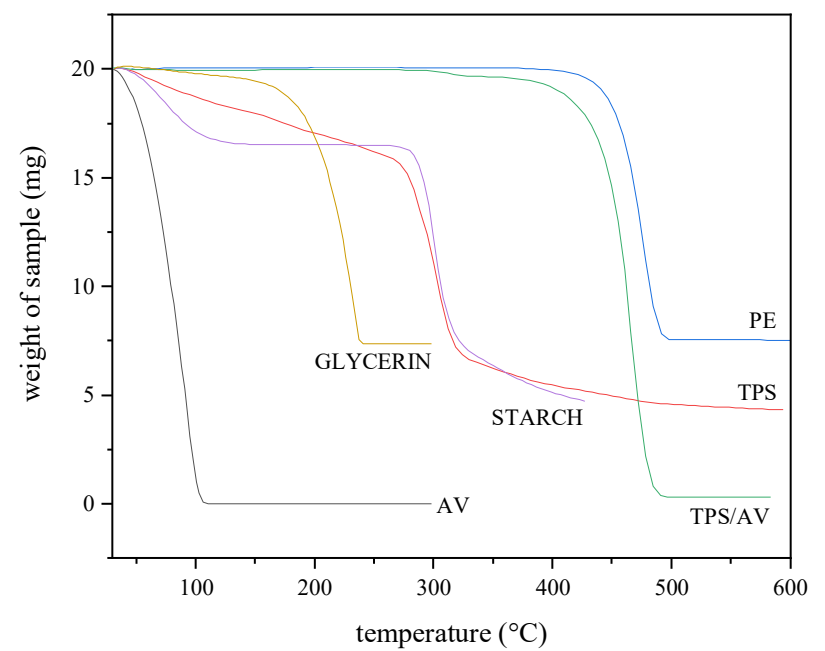

Fig. 8a Thermogravimetric graph for AV gel, TPS film, TPS/AV film and PE film

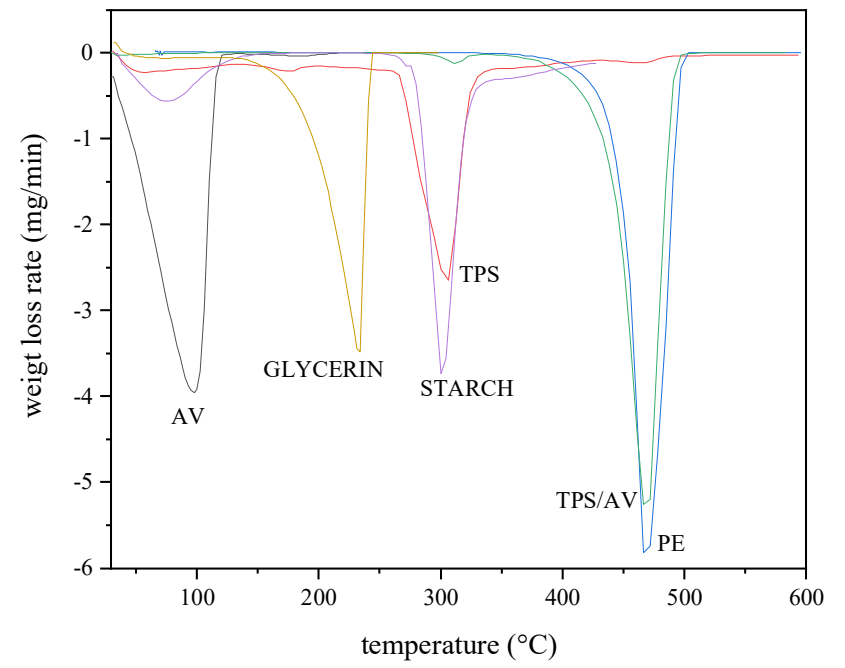

Fig. 8b Derivative thermogravimetric graph for AV gel, TPS film, TPS/AV film and PE film

The decomposition of glycerine-starch continued at $280^{\circ} \mathrm{C}$ representing the evaporation of glycerine-starch, which initially the $T_{d}$ for glycerine and starch was $133.87^{\circ} \mathrm{C}$ and $262{ }^{\circ} \mathrm{C}$, respectively. The $\mathrm{T}_{\mathrm{d}}$ of TPS shifted to a higher value showing glycerine and starch combined. Similar changes shown by the addition of glycerol into corn-starch; the $T_{d}$ at $10 \%$ degradation increased from $113.3{ }^{\circ} \mathrm{C}$ to $197.2^{\circ} \mathrm{C}$ [48]. Others found glycerin-starch decompose at $160^{\circ} \mathrm{C}$ and $290^{\circ} \mathrm{C}$ while starch decomposed at $330{ }^{\circ} \mathrm{C}$. TPS/AV and PE decomposition temperature were observed at 354.70 and $366.86{ }^{\circ} \mathrm{C}$, respectively. LDPE experienced a maximum temperature of $478.32{ }^{\circ} \mathrm{C}$, and decomposition temperature was $355{ }^{\circ} \mathrm{C}$ [38]. The addition of AV in TPS shows tremendous changes on the $T_{d}$, which is almost similar to PE film. These results are supported by FTIR transmittance peak where one similar functional group of $\mathrm{PE}$ observed in TPS/AV that suggested TPS/AV shows similar PE thermal character. Complete degradation was observed for AV gel and TPS/AV, while PE, glycerine, starch powder, and TPS film showed some residue with $7.53 \mathrm{mg}, 7.38 \mathrm{mg}, 4.73 \mathrm{mg}$, $4.32 \mathrm{mg}$, respectively. Hence, degradation of TPS/AV can reduce the greenhouse gas emission/unwanted residue rather than PE film as the degradation of $\mathrm{PE}$ will release toxic gas to the environment.

The thermal analysis proceeded on the combination of all raw materials at different formulations. Fig. 9a and Fig. 9b show the thermogravimetric and derivative thermogravimetric graphs for the films. A similar graph pattern was observed for all films showing three important stages occurred; 1) evaporation of physisorbed water, maximum temperature $\left(\mathrm{T}_{\max }\right)$ between $\left.107.10-107.88^{\circ} \mathrm{C}, 2\right)$ evaporation of glycerine-starch, $\mathrm{T}_{\max }$ between 298.75 $304.81^{\circ} \mathrm{C}$, and 3) decomposition of PE and TPS-AV, $\mathrm{T}_{\max }$ between $474.63-477.53{ }^{\circ} \mathrm{C}$. A combination of banana starch and AV gel obtained a similar trend of decomposition covered water evaporation $\left(\mathrm{T}_{\max }, 105^{\circ} \mathrm{C}\right)$ and decomposition of amylose $\left(\mathrm{T}_{\max }, 180^{\circ} \mathrm{C}\right)$ and amylopectin $\left(\mathrm{T}_{\max }, 250^{\circ} \mathrm{C}\right)$ [49]. The $T_{\max }$ almost similar for all films, but the degradation rate differed with a different formulation. Only a slight change occurred at $\mathrm{T}_{\max }$ of glycerine-starch. At constant $9 \mathrm{~g}$ and $18 \mathrm{~g}$ of TPS, reduction of AV caused increment of $\mathrm{T}_{\max }$, from $301.94{ }^{\circ} \mathrm{C}$ to $303.34{ }^{\circ} \mathrm{C}$ and 298.75 to 304.81 , respectively. The amount of starch gives changes to the degradation rate of the films. At stage 2, evaporation of glycerine-starch, 21PE/9TPS/0.6 AV or $1.98 \mathrm{AV}$ undergo 0.87 and 0.69 $\mathrm{mg} / \mathrm{min}$ while $21 \mathrm{PE} / 18 \mathrm{TPS} / 0.6 \mathrm{AV}$ or $1.98 \mathrm{AV}$ was 1.07 and $1.37 \mathrm{mg} / \mathrm{min}$. Higher TPS contributed to high intensity of degradation rate at the evaporation of glycerine starch. This condition may be attributed to the depolymerization and decomposition process of the glycerine starch that improved with AV. The same condition occurred for acetylated and deacetylated groups in the modified starch nanoparticles [49]. For the third stage, the higher TPS content leads to a low intensity of degradation rate due to two decomposition taking place at the same temperature range, decomposition of $\mathrm{PE}$ and decomposition of TPS/AV. Tomy, [24] mentioned that more TPS creates greater glycerol-flour interaction with the presence of AV. Thus, it suggested that the degradation rate was lower, and intensity increased.

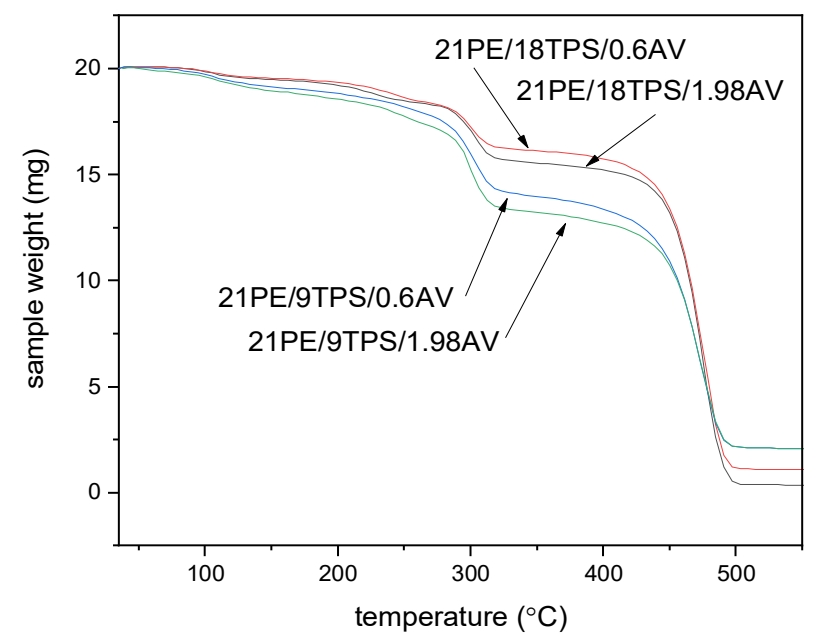

Fig. 9a Thermogravimetric graph PE/TPS/AV film at different formulation 


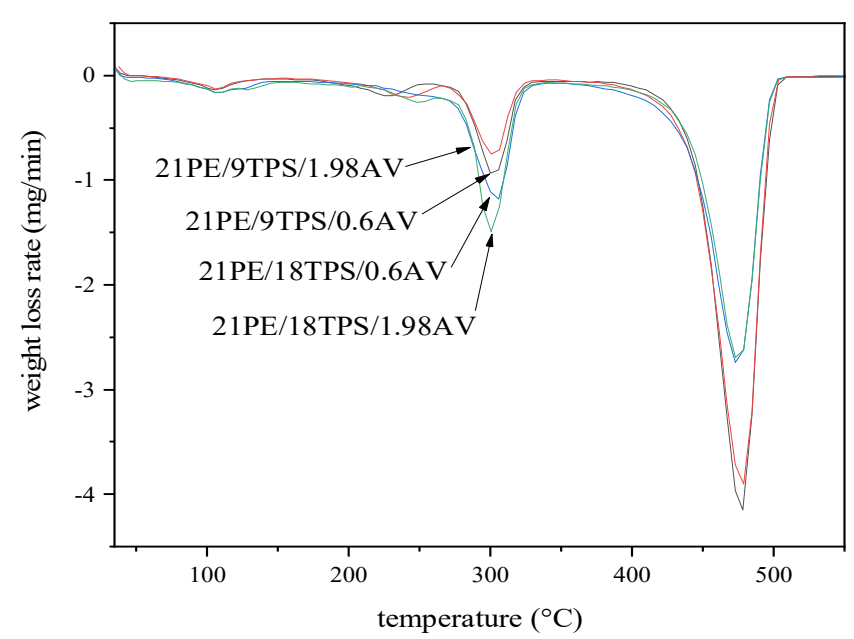

Fig. 9b Derivative thermogravimetric graph PE/TPS/AV film at different formulation

4) DSC: DSC curves for the $1^{\text {st }}$ heating process were shown in Fig. 10, representing the thermal properties of AV, TPS, PE, and TPS/AV. It shows that only one endothermic peak obtained for AV, TPS, and PE which the melting temperature $\left(\mathrm{T}_{\mathrm{m}}\right)$ value was 125,167 , and $107^{\circ} \mathrm{C}$.

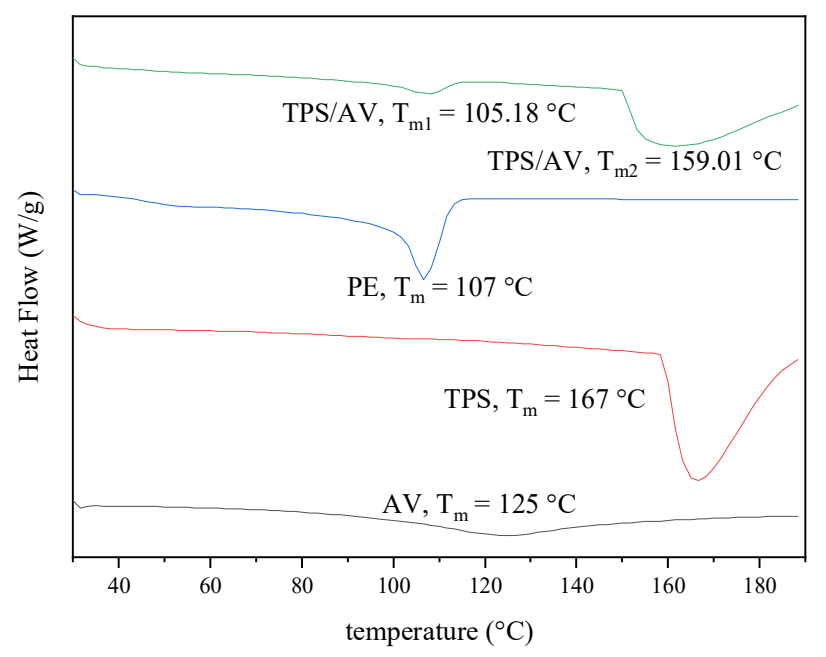

Fig. 10 First heating DSC curve for raw materials

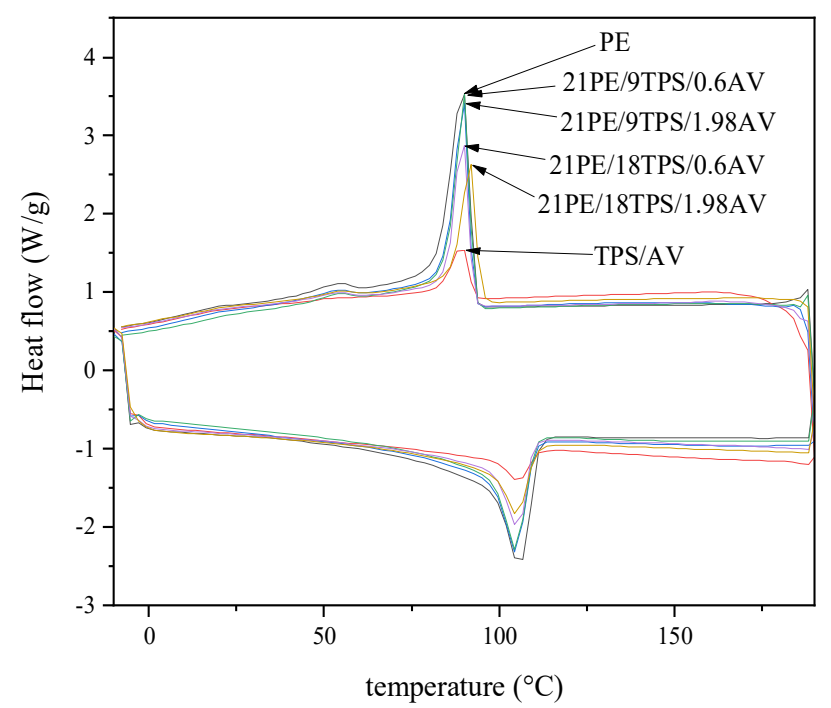

Fig. 11: DSC curve for cooling and second heating for PE film, TPS/AV film, and PE/TPS/AV film at a different formulation
In contrast, two endothermic peaks appeared for the combination of TPS/AV for $\mathrm{T}_{\mathrm{m} 1}, 105.18{ }^{\circ} \mathrm{C}$, and $\mathrm{T}_{\mathrm{m} 2}$, $159.01{ }^{\circ} \mathrm{C}$, both shifted to lower value from $125^{\circ} \mathrm{C}\left(\mathrm{T}_{\mathrm{m}}, \mathrm{AV}\right)$ and $167{ }^{\circ} \mathrm{C}\left(\mathrm{T}_{\mathrm{m}}, \mathrm{TPS}\right)$. The previous study found $\mathrm{T}_{\mathrm{m}}$ for commercial AV was $50-75{ }^{\circ} \mathrm{C}$ depending on the phase and the active content inside AV gel [50], $167.51^{\circ} \mathrm{C}, \mathrm{T}_{\mathrm{m}}$ for TPS [51], and $108{ }^{\circ} \mathrm{C}, \mathrm{T}_{\mathrm{m}}$ for PE [52]. Fig. 11 shows the DSC cooling and heating curve for PE film, TPS/AV film and PE/TPS/AV films. It presents one endothermic peak and one exothermic peak for all films. Table 5 listed the parameters obtained from the DSC cooling and heating curve, as shown in Fig. 11.

From Table 5, the highest $\mathrm{T}_{\mathrm{m}}$ obtained by $\mathrm{PE}$ and combination of TPS/AV produced almost the same $\mathrm{T}_{\mathrm{m}}$ as PE because of the presence of the $\mathrm{C}-\mathrm{H}$ group, as explained in section FTIR. The $\mathrm{T}_{\mathrm{m}}$ of PE reduced with the addition of TPS/AV because the PE relaxation decreased where this blending caused steric hindrance that prevents PE movement [14]. The hydrophobic character in TPS/AV inhibited PE relaxation. Hammache [4] mentioned that water and glycerol in TPS with low solubility caused a reduction in $\mathrm{T}_{\mathrm{m}}$ of PE. Allessandra [53] stated that $\mathrm{T}_{\mathrm{m}}$ lowered was due to a reduction in molar mass due to either decrement of crystalline size and/or impurity in the sample.

\section{TABLE V}

CRYSTALLIZATION AND MELTING PROCESS PARAMETERS

\begin{tabular}{llllll}
\hline Films & $\mathbf{T}_{\mathbf{m}}$ & $\boldsymbol{\Delta}_{\mathbf{m}}$ & $\mathbf{T}_{\mathbf{c}}$ & $\boldsymbol{\Delta H}_{\mathbf{c}}$ & $\mathbf{X}_{\mathbf{c}}$ \\
\hline PE & 105.18 & 69.86 & 90.32 & 65.89 & 23.84 \\
TPS/AV & 105.05 & 14.18 & 89.63 & 13.14 & 4.84 \\
21PE/9TPS/1.98AV & 103.87 & 53.1 & 90.34 & 49.88 & 18.12 \\
21PE/9TPS/0.6AV & 103.89 & 38.99 & 90.65 & 50.74 & 13.31 \\
21PE/18TPS/0.6AV & 104.93 & 54.64 & 89.89 & 38.67 & 18.65 \\
21PE/18TPS/1.98AV & 104.65 & 36.92 & 92.15 & 35.81 & 12.60 \\
\hline
\end{tabular}

$\mathrm{T}_{\mathrm{m}}$, melting temperature, $\Delta \mathrm{H}_{\mathrm{m}}$, enthalpy of fusion, $\mathrm{T}_{\mathrm{c}}$, crystallization temperature, $\Delta \mathrm{H}_{\mathrm{c}}$. enthalpy of crystallization, $\mathrm{X}_{\mathrm{c}}$, degree of crystallinity

Incorporating AV into TPS produced a semicrystalline structure. The presence of crystallization temperature $\left(T_{c}\right)$ in TPS/AV supports the FTIR findings showing some crystalline peak (C-H functional group) presence. The $\mathrm{T}_{\mathrm{c}}$ obtained for $\mathrm{PE}$ was $90.32{ }^{\circ} \mathrm{C}$. The $\mathrm{T}_{\mathrm{c}}$ of PE that consists of TPS/AV shows insignificant changes, but the $\Delta \mathrm{Hc}$ changed drastically with TPS/AV. Lower TPS gave higher $\Delta \mathrm{H}_{\mathrm{c}}$ (more energy released) than higher TPS, and higher AV at constant TPS gave a lower $\Delta \mathrm{H}_{\mathrm{c}}$. (less energy released). Similar results were found by others in which an increasing amount of TPS reduced the $\Delta \mathrm{H}_{\mathrm{c}}$ [4]. The $\Delta \mathrm{H}_{\mathrm{c}}$. represents the crystal's growth in the polymer, which shows that PE has the highest crystal growth and is proved by the value of the degree of crystallinity $\left(\mathrm{X}_{\mathrm{c}}\right)$. The $\mathrm{X}_{\mathrm{c}}$ was reduced in PE/TPS/AV because TPS/AV dispersion in the PE matrix had disturbed the film's structure. TPS/AV shows the lowest $X_{c}$ because of the small value of enthalpy of fusion. The small $\Delta \mathrm{H}_{\mathrm{m}}$ suggests that the $\mathrm{C}-\mathrm{H}$ chain structure developed by TPS/AV was not as long as the $\mathrm{C}-\mathrm{H}$ chain presence in PE. The PE chain structure has been disturbed by TPS/AV and reduced the $\Delta \mathrm{H}_{\mathrm{m}}$ and $\mathrm{X}_{\mathrm{c}}$. The hydrophilic phase of TPS/AV hindered starch recrystallization, thus giving a lower amount of $\mathrm{X}_{\mathrm{c}}$. Allesandra [53] mentioned that more linear structures in synthetic polymers destroyed and affected 
the size of synthetic polymer crystal structure limited by amylopectin. Thus, it suggested a reduction in $\Delta \mathrm{H}_{\mathrm{m}}$. Similar conditions were obtained with the addition of starch into linear low-density polyethylene (LLDPE) [14].

\section{CONCLUSION}

The findings presented in this paper suggested that AV has potential criteria that can create a crosslinking between TPS (starch molecules) that contributed to forming a more substantial functional group that represents PE's primary FTIR spectrum. Thus, it contributed to the high thermal degradation of TPS with AV inside the film. At the same time, the thermal properties, especially the enthalpy of crystallization, increased due to $\mathrm{AV}$-caused $\mathrm{PE}$ peaks obtained in TPS. Then, it improved the crystallinity percentage. However, at the presented PE/TPS/AV, the optimum formula obtained was $18.91 \mathrm{PE} / 16.54 \mathrm{TPS} / 0.84 \mathrm{AV}$ and $\mathrm{PE}$ become significant for the film. So, a new range should be applied to determine better changes on PE film so that a small percentage of PE with a high percentage of TPS can be combined to obtain better degradation PE/TPS ratio.

\section{ACKNOWLEDGEMENT}

Special appreciation to the Ministry of Higher Education Malaysia supports this work through two grants, 600$\begin{array}{llll}\mathrm{RMC} / \mathrm{GPK} & 5 / 3 & (146 / 2020) & \text { and }\end{array}$ RAGS/1/2015/TK02/UITM/03/1.

\section{REFERENCES}

[1] D. Datta and G. Halder, "Effect of media on degradability, physicomechanical and optical properties of synthesized polyolefinic and PLA film in comparison with casted potato/corn starch biofilm," Process Saf. Environ. Prot., vol. 124, pp. 39-62, 2019.

[2] M. Ahmadi, T. Behzad, R. Bagheri, and P. Heidarian, "Effect of cellulose nanofibers and acetylated cellulose nanofibers on the properties of low-density polyethylene/thermoplastic starch blends," Polym. Int., vol. 67, no. 8, pp. 993-1002, 2018.

[3] T. Mazerolles, M. C. Heuzey, M. Soliman, H. Martens, R. Kleppinger, and M. A. Huneault, "Development of multilayer barrier films of thermoplastic starch and low-density polyethylene," J. Polym. Res., vol. 27 , no. 2 , pp. $1-15,2020$.

[4] Y. Hammache, A. Serier, and S. Chaoui, "The effect of thermoplastic starch on the properties of polypropylene/high density polyethylene blend reinforced by nano-clay," Mater. Res. Express, vol. 7, no. 2, pp. $1-13,2020$

[5] T. Mazerolles, M. C. Heuzey, M. Soliman, H. Martens, R. Kleppinger, and M. A. Huneault, "Development of co-continuous morphology in blends of thermoplastic starch and low-density polyethylene," Carbohydr. Polym., vol. 206, no. June 2018, pp. 757-766, 2019.

[6] R. Mani et al., "Biodegradability study by FTIR and DSC of polymers films based on polypropylene and Cassava starch," Orbital, vol. 11, no. 8, pp. 71-82, Apr. 2019

[7] N. Khanoonkon, R. Yoksan, and A. A. Ogale, "Morphological characteristics of stearic acid-grafted starch-compatibilized linear low density polyethylene/thermoplastic starch blown film," Eur. Polym. J., vol. 76, pp. 266-277, 2016.

[8] J. Aburto et al., "Properties of octanoated starch and its blends with polyethylene," Carbohydr. Polym., vol. 34, no. 1-2, pp. 101-112, 1997.

[9] A. Kaboorani, N. Gray, Y. Hamzeh, and A. Abdulkhani, "Tailoring the low-density polyethylene - thermoplastic starch composites using cellulose nanocrystals and compatibilizer," Polym. Test., vol. 93, p. 107007,2021

[10] A. A. O. Nattaporn Khanoonkona, Rangrong Yoksana, "Effect of stearic acid-grafted starch compatibilizer on properties oflinear low density polyethylene/thermoplastic starch blown film," Carbohydr. Polym., vol. 137, pp. 165-173, 2016.

[11] D. Datta and G. Halder, "Enhancing degradability of plastic waste by dispersing starch into low density polyethylene matrix," Process Saf. Environ. Prot., vol. 114, pp. 143-152, 2018.

[12] M. Sabetzadeh, R. Bagheri, and M. Masoomi, "Morphology and rheological properties of compatibilized low-density polyethylene/linear low-density polyethylene/thermoplastic starch blends," J. Appl. Polym. Sci., vol. 134, no. 16, pp. 1-9, 2017.

[13] D. M. Nguyen, T. V. V. Do, A. C. Grillet, H. Ha Thuc, and C. N. Ha Thuc, "Biodegradability of polymer film based on low density polyethylene and cassava starch," Int. Biodeterior. Biodegrad., vol. 115 , pp. $257-265,2016$.

[14] T. Panrong, T. Karbowiak, and N. Harnkarnsujarit, "Effects of acetylated and octenyl-succinated starch on properties and release of green tea compounded starch/LLDPE blend films," J. Food Eng., vol. 284 , p. $110057,2020$.

[15] R. Thipmanee, S. Lukubira, A. A. Ogale, and A. Sane, "Enhancing distributive mixing of immiscible polyethylene/thermoplastic starch blend through zeolite ZSM-5 compounding sequence," Carbohydr. Polym., vol. 136, pp. 812-819, 2015.

[16] T. Panrong, T. Karbowiak, and N. Harnkarnsujarit, "Thermoplastic starch and green tea blends with LLDPE films for active packaging of meat and oil-based products," Food Packag. Shelf Life, vol. 21, p. $100331,2019$.

[17] N. Amigo et al., "Effect of starch nanoparticles on the crystallization kinetics and photodegradation of high density polyethylene," Compos. Part B Eng., vol. 174, p. 106979, 2019.

[18] N. Gray, Y. Hamzeh, A. Kaboorani, and A. Abdulkhani, "Influence of cellulose nanocrystal on strength and properties of low density polyethylene and thermoplastic starch composites," Ind. Crops Prod., vol. 115, pp. 298-305, 2018.

[19] A. B. Martins, A. K. Cattelan, and R. M. C. Santana, "How the compatibility between polyethylene and thermoplastic starch can be improved by adding organic acids?," Polym. Bull., vol. 75, no. 5, pp. 2197-2212, 2018.

[20] R. Radfar et al., "Optimization of antibacterial and mechanical properties of an active LDPE/starch/nanoclay nanocomposite film incorporated with date palm seed extract using D-optimal mixture design approach," Int. J. Biol. Macromol., vol. 158, pp. 790-799, 2020.

[21] T. J. Gutiérrez and G. González, "Effect of Cross-Linking with Aloe vera Gel on Surface and Physicochemical Properties of Edible Films Made from Plantain Flour," Food Biophys., vol. 12, no. 1, pp. 11-22, 2017.

[22] S. R. Kanatt and S. H. Makwana, "Development of active, waterresistant carboxymethyl cellulose-poly vinyl alcohol-Aloe vera packaging film," Carbohydr. Polym., vol. 227, p. 115303, 2020.

[23] G. F. El Fawal, A. M. Omer, and T. M. Tamer, "Evaluation of antimicrobial and antioxidant activities for cellulose acetate films incorporated with Rosemary and Aloe Vera essential oils," J. Food Sci. Technol., vol. 56, no. 3, pp. 1510-1518, 2019.

[24] T. J. Gutiérrez and K. Álvarez, "Physico-chemical properties and in vitro digestibility of edible films made from plantain flour with added Aloe vera gel," J. Funct. Foods, vol. 26, pp. 750-762, 2016.

[25] R. Ortega-Toro, S. Collazo-Bigliardi, J. Roselló, P. Santamarina, and A. Chiralt, "Antifungal starch-based edible films containing Aloe vera," Food Hydrocoll., vol. 72, pp. 1-10, 2017.

[26] L. Yesappa et al., "Investigation of the Structure, Optical and Electrical Properties of Lithium Perchlorate Doped Polyaniline Composite: Aloe Vera Used as a Bio-Plasticizer," J. Electron. Mater., vol. 46, no. 12, pp. 6965-6976, 2017.

[27] M. I. Pinzon, L. T. Sanchez, O. R. Garcia, R. Gutierrez, J. C. Luna, and C. C. Villa, "Increasing shelf life of strawberries (Fragaria ssp) by using a banana starch-chitosan-Aloe vera gel composite edible coating," Int. J. Food Sci. Technol., vol. 55, no. 1, pp. 92-98, 2019.

[28] M. I. Pinzon, O. R. Garcia, and C. C. Villa, "The influence of Aloe vera gel incorporation on the physicochemical and mechanical properties of banana starch-chitosan edible films," J. Sci. Food Agric., vol. 98 , no. 11, pp. 4042-4049, 2018.

[29] U. Verma, R. Rajput, and J. B. Naik, "Development and characterization of Fast Dissolving Film of Chitosan embedded Famotidine Using 32 Full Factorial Design Approach," Mater. Today Proc., vol. 5, no. 1, pp. 408-414, 2018.

[30] P. R. Vuddanda, M. Montenegro-Nicolini, J. O. Morales, and S. Velaga, "Effect of plasticizers on the physico-mechanical properties of pullulan based pharmaceutical oral films," Eur. J. Pharm. Sci., vol. 96, pp. 290-298, 2017.

[31] X. Chen, L. Zhou, X. Pan, J. Hu, Y. Hu, and S. Wei, "Effect of different compatibilizers on the mechanical and thermal properties of starch/polypropylene blends," J. Appl. Polym. Sci., vol. 133, no. 17, 
pp. 1-7, 2016.

[32] M. Karimi and D. Biria, "The promiscuous activity of alpha-amylase in biodegradation of low-density polyethylene in a polymer-starch blend," Sci. Rep., vol. 9, no. 1, pp. 1-10, 2019.

[33] S. F. Abd Karim, J. B. Jai, K. H. Ku Hamid, and A. W. Abdul Jalil, "Characteristics and mechanical properties changes due to incorporation of aloe vera in polyethylene-based film," Sci. Res. J., vol. 17, no. 2, pp. 61-80, 2020.

[34] D. Datta and G. Halder, "Blending of phthalated starch and surface functionalized rice husk extracted nanosilica with LDPE towards developing an efficient packaging substitute," Environ. Sci. Pollut. Res., vol. 27, no. 2, pp. 1533-1557, 2020.

[35] M. Sabetzadeh, R. Bagheri, and M. Masoomi, "Effect of Oxidized Starch on Morphology, Rheological and Tensile Properties of LowDensity Polyethylene/Linear Low-Density Polyethylene/Thermoplastic Oxidized Starch Blends," J. Polym. Environ., vol. 26, no. 6, pp. 2219-2226, 2018.

[36] R. Minjares-Fuentes, A. Femenia, F. Comas-Serra, and V. M. Rodríguez-González, "Compositional and structural features of the main bioactive polysaccharides present in the aloe vera plant," $J$. AOAC Int., vol. 101, no. 6, pp. 1711-1719, 2018.

[37] L. Wang et al., "Effects of fatty acid chain length on properties of potato starch-fatty acid complexes under partially gelatinization," Int J. Food Prop., vol. 21, no. 1, pp. 2121-2134, 2018.

[38] S. Fatma, A. Karim, J. Jai, K. Halim, K. Hamid, and A. Wafi, "Effect of crude palm oil , Aloe vera, glycerol, and starch on characteristics and mechanical properties of polyethylene film," Malaysian J. Chem. Eng. Technol., vol. 3, no. 1, pp. 16-24, 2020.

[39] L. Panahi, M. Gholizadeh, and R. Hajimohammadi, "Investigating the degradability of polyethylene using starch, oxo-material, and polylactic acid under the different environmental conditions," AsiaPacific J. Chem. Eng., vol. 15, no. 1, pp. 1-12, 2020.

[40] O. ard Saibuatong and M. Phisalaphong, "Novo aloe vera-bacterial cellulose composite film from biosynthesis," Carbohydr. Polym., vol. 79, pp. 455-460, 2010.

[41] A. Ramírez-Hernández et al., "Thermal, morphological and structural characterization of a copolymer of starch and polyethylene," Carbohydr. Res., vol. 488, p. 107907, 2020.

[42] M. P. Ong-ard Saibuatong, "Novo aloe vera-bacterial cellulose composite film from biosynthesis," Carbohydr. Polym., vol. 79, pp. 455-460, 2010.
[43] C. Agudelo-Cuartas, D. Granda-Restrepo, P. J. A. Sobral, and W. Castro, "Determination of mechanical properties of whey protein films during accelerated aging: Application of FTIR profiles and chemometric tools," J. Food Process Eng., vol. 44, no. 5, p. e13477, 2020 .

[44] L. Q. Khor and K. Y. Cheong, "Aloe vera gel as natural organic dielectric in electronic application," J. Mater. Sci. Mater. Electron., vol. 24, no. 7, pp. 2646-2652, 2013.

[45] S. S. and G. H. Datta, Deepshikha, "Effect of thickness and starch phthalate/starch content on the degradability of LDPE/silane-modified nanosilica films: a comparative parametric optimization," Polym. Bull., vol. 78, pp. 2287-2328, 2021.

[46] X. Liu et al., "Thermal degradation and stability of starch under different processing conditions," Starch/Starke, vol. 65, pp. 48-60, 2013.

[47] J. Chen, X. Wang, Z. Long, S. Wang, J. Zhang, and L. Wang, "Preparation and performance of thermoplastic starch and microcrystalline cellulose for packaging composites: Extrusion and hot pressing," Int. J. Biol. Macromol., vol. 165, pp. 2295-2302, 2020.

[48] N. Nordin, S. H. Othman, S. A. Rashid, and R. K. Basha, "Effects of glycerol and thymol on physical, mechanical, and thermal properties of corn starch films," Food Hydrocoll., vol. 106, p. 105884, 2020.

[49] L. Nieto-Suaza, L. Acevedo-Guevara, L. T. Sánchez, M. I. Pinzón, and C. C. Villa, "Characterization of Aloe vera-banana starch composite films reinforced with curcumin-loaded starch nanoparticles," Food Struct., vol. 22, p. 100131, 2019.

[50] C. I. Nindo, J. R. Powers, and J. Tang, "Thermal Properties of Aloe Vera Powder and Rheology of Reconstituted Gels," Trans. ASABE, vol. 53, no. 4, pp. 1193-1200, 2010.

[51] E. Stasi et al., "Biodegradable carbon-based ashes/maize starch composite films for agricultural applications," Polymers (Basel)., vol. 12 , no. 3, pp. 1-16, 2020.

[52] D. Li, L. Zhou, X. Wang, L. He, and X. Yang, "Effect of Crystallinity of Polyethylene with Different Densities on Breakdown Strength and Conductance Property," Materials (Basel)., vol. 12, no. 11, p. 1746 , 2019.

[53] A. L. Da Róz, M. D. Zambon, A. A. S. Curvelo, and A. J. F. Carvalho, "Thermoplastic starch modified during melt processing with organic acids: The effect of molar mass on thermal and mechanical properties," Ind. Crops Prod., vol. 33, no. 1, pp. 152-157, 2011. 